\title{
Equivocal plantar responses: a clinical and electromyographic study
}

\author{
J. VAN GIJN \\ From the Department of Neurology, Academic Hospital Dijkzigt, \\ Rotterdam, The Netherlands
}

SYNOPSIS Thirty patients in whom others found equivocal plantar reflexes were studied clinically and electromyographically (EMG-of flexor hallucis brevis, extensor hallucis longus, and tibialis anterior), during mechanical stimulation of the sole. Bias of recording or interpretation of EMG was excluded. The study was repeated after one week; the EMG outcome was reproducible in 26 patients $(87 \%)$. Of these 26 , a pathological reflex was suspected by the clinician in 17 , but shown by EMG in only six patients. Compared with the 'final' diagnosis, false-pathological EMG results did not occur; conversely, EMG criteria were wide enough to demonstrate expected, but clinically unconvincing, Babinski signs. Various factors that cause false impressions in the routine situation could be identified. Provided one has some experience with reference groups, EMG can improve clinical interpretation of equivocal plantar responses.

The upgoing toe is not an oracle, but part of a disinhibited flexion reflex (Walshe, 1914), and indicates abnormal recruitment of the extensor hallucis longus - a physiological flexor muscleinto synergy with the tibialis anterior (Landau and Clare, 1959; van Gijn, 1975). Even slight activity in the extensor hallucis longus causes movement of the great toe, because the load is small compared with that of other flexor muscles of the leg.

Sometimes, however, it is difficult to determine the direction of hallux movements. Decisions are then often arbitrary. This was illustrated by the variety of opinions among 28 neurologists who saw an equivocal plantar reflex on film: one considered it a definite Babinski sign, 16 a possible Babinski sign, three an absent plantar response, seven a possible flexor response, and one a definite flexor response. Uncertain plantar responses are no exception and may give rise to second thoughts about the diagnosis. Therefore, it was considered to be of interest to do an electromyographic (EMG) study in this group of cases, recording from the effectors of the plantar reflex, flexor hallucis brevis (FHB) and extensor hallucis longus (EHL), and also from the tibialis anterior (TA), to investigate the time relation to the flexion reflex.

Stimulation was mechanical, according to the usual clinical method: slow stroking of the lateral plantar border and the transverse arch with a semi-sharp object (Dohrmann and Nowack, 1973). Reflexes evoked by short electrical stimuli do not discriminate between patients with a Babinski response and normal subjects (van Gijn, 1975); there is also some overlap when pin pricks are applied to the sole by a vibrator (Nakanishi et al., 1974). Another important advantage of the familiar mechanical stimulus is that it allows feedback towards the clinical situation: muscle fibre potentials reflect the discharge pattern of motoneurones more exactly than a quick succession of movements, at least theoretically, and the time sequence of these discharges can be studied on film.

To test the reliability of the technique, it was repeated on each patient a week later, and the results of all investigations were judged without any clues about patient or diagnosis. The outcome in each patient was compared with the author's separate clinical findings and with the final neurological diagnosis. 


\section{METHODS}

SELECTION AND RECORDING Within six months, 30 patients were referred from the neurology ward or from the outpatient department because of equivocal plantar responses, on which the resident and consultant neurologist agreed. They jointly classified the plantar reflex on a form, choosing from five possibilities: extensor, extensor?, absent, flexor?, and flexor. The form was sent to the secretary of the study; the author in turn was notified only of the patient's name and the side where the clinicians considered the plantar reflex most equivocal (the inconvenience of the procedure to the patient did not permit investigation of both feet at the same time). The day before EMG, the author himself investigated the plantar reflexes in the usual way, and made notes about other motor phenomena of the legs as well. Although he was unaware of the suspected diagnosis, this might bias the subsequent recording. Therefore, electromyography was performed without visual or auditory feedback from the oscilloscope.

The technique of recording from FHB, EHL, and TA is described in an earlier paper (van Gijn, 1975). Because a two-channel oscilloscope was used, pictures were taken from three subsequent reflexes in FHB and EHL, and from another three in TA and EHL. A reflex was rejected and repeated only when the tracing was technically insufficient. The six pictures were mounted on a blank card and handed in to the secretary, together with the protocol of the experiment and the notes of the day before. After one week, the entire procedure was repeated. At the end of the study, the 60 cards, identified only through a code number given by the secretary, were interpreted five times, on separate occasions. The patients were followed up for four to 10 months.

INTERPRETATION OF EMG Criteria for a pathological EHL reflex, representing a Babinski sign, were based on the earlier study of 49 control subjects and 22 patients with a Babinski response:

1. The EHL reflex should coincide with a reflex in TA. It may be true that, in patients with extremely active flexion reflexes, it is often possible to evoke an almost isolated Babinski response by merely touching the sole (local sign), but in this study stimulation was sufficiently strong to evoke a full flexion reflex, if present. On the other hand, isolated potentials in the EHL could result from irritation by the tip of the recording electrode, especially when the needle was levered by voluntary or reflex activity of other muscles through which it was inserted.

2. Potentials should be dense enough not to be separately identifiable ('interference pattern'-that is, at $500 \mathrm{~ms} / \mathrm{cm}$ time base) either continuously or in regular clusters (clonic reflex).

3. Larger potentials should appear at the middle of the reflex, indicating recruitment of motoneurones of increasing size (Henneman et al., 1974), so that, ideally, a spindle shape is formed. It should, however, be kept in mind that, besides motor unit size, electrode position is another factor determining potential amplitude.

4. The end of the reflex should be visible: voluntary withdrawal tends to hold on for a few seconds, and flexor spasms are hardly to be expected in this group of patients.

5. There should be no concomitant reflex in FHB.

Judgements were made according to five possibilities (Figure). If not all qualifications for a pathological EHL reflex were met each time, a probable EHL reflex could be rated; this was minimally defined by the presence of the first two criteria twice out of six times. When neither of these pathological categories was applicable, the result was considered normal, and a choice was made between definite or probable FHB reflex ( $c f$. criteria 2, 3, and 4 for EHL) or no reflex activity at all. Strictly speaking, an absent reflex can be abnormal when a FHB response is found contralaterally, but this was not investigated

\section{RESULTS}

OBSERVER CONSISTENCY The overall standard of judgement scarcely varied throughout the five sittings. When pathological marks are considered (assigning +1 for a probable EHL reflex, +2 for a definite EHL reflex), there was, in comparison with the first time, a small decrease of $1 \%, 2 \frac{1}{2} \%, 2 \%$, and $2 \frac{1}{2} \%$ of maximum variation respectively.

Intra-observer variation (contradiction pathological-not pathological) occurred in five of the 60 sets of pictures. In four, only one of the five readings was at variance with the others. These exceptions were disregarded when both investigations in each patient were compared (EMG consistency), as they did not appear in the same pair, so that the chance of a contradictory outcome was only one in 10 in these four patients. In one further set, dissension occurred twice.

Of the remaining 55 sets, 43 had been classified identically on the five-point scale on each of the five occasions. In 12, there was some shift within the same group-that is, FHB reflex, probable FHB reflex or no reflex on the one side 
A
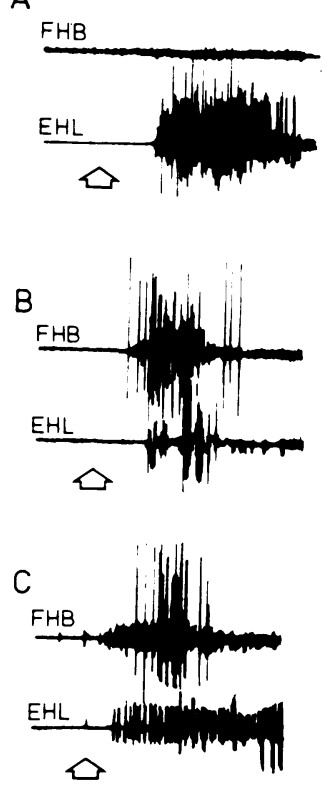
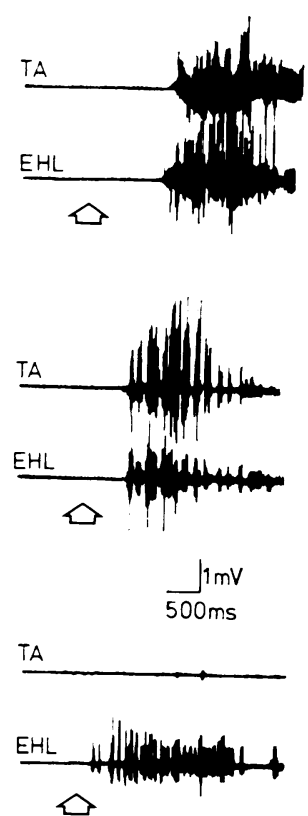

FIGURE Patterns of activity in EHL. Beginning of stimulation marked by arrows. A. Pathological EHL reflex: synchronous with TA, merged potentials, spindle-like, no FHB reflex. B. Probably pathological EHL reflex: synchronous with $T A$, merged potentials in clusters, some recruitment, FHB reflex present. C. No pathological EHL reflex: TA silent, no clear merging of potentials, no recruitment or decreasing of activity, FHB reflex present.

versus $\mathrm{EHL}$ reflex or probable EHL reflex on the other.

EMG CONSISTENCY After interpretation, the patient code was broken and the two sets for each patient were matched and compared. It appeared that repetition of the EMG examination led to a similar opinion in 26 of the 30 patients $(87 \%)$. Twenty pairs were both interpreted as normal, six both as pathological.

Of the four mismatches, two were rated normal once and possibly pathological the other time, one normal (absent) versus definitely pathological. The latter patient and one of the former two showed on clinical examination bilateral but exceptionally fast upgoing toes, with the additional problem that no corresponding lesion could be found; they will be discussed separately. The fourth pair contained the set in

which two readings contradicted the other three, while the twin set showed a definite EHL reflex. True variation of the plantar reflex within one week is, of course, possible, but was probably not a factor here.

SECOND OBSERVER To know whether it is easy for an electromyographer not familiar with plantar reflexes to decide whether a pathological EHL reflex is present or not, a nurse with three years' experience as an EMG assistant was asked to interpret the photographs in the same way as the author. The data from patients with a Babinski sign and control subjects were shortly discussed beforehand. Compared with the author, about twice as many sets were rated pathological, including patterns that may be seen in control subjects. Seven pairs could not be matched because of observer variation (two scores opposite to the other three in at least one of both sets); five more pairs did not fit. Clearly some experience with reference groups is necessary.

EMG RESULT AND CLINICAL OPINION The EMG indicated a pathological reflex considerably less often than the clinical judgement of the referring neurologist (this opinion was never definitely flexor or extensor, so that in practice a choice was made between probably extensor versus absent or probably flexor). Of the 20 patients in whom a Babinski sign was suspected, the EMG was pathological in four, normal in 13, and contradictory in three. In the remaining 10 patients, tentatively classified as normal by the neurologist, the distribution of EMG results was similar: two pathological, seven normal, one contradictory. The identical proportions of EMG categories in these two groups can be taken to illustrate that these plantar responses were truly equivocal. However, the validity of the EMG study must be substantiated by further clinical data concerning individual patients.

EMG RESULT AND NEUROLOGICAL DIAGNOSIS The clinical diagnosis in the patients was not influenced by this study; otherwise, the argument would be circular. Even then, it is obviously impossible to 'prove' the precision of the EMG outcome by referring to the neurological label: a Babinski sign can be lacking in the presence of 
TABLE 1

PATIENTS SHOWING EQUIVOCAL PLANTAR RESPONSE AS ONLY POSSIBLE SIGN OF UPPER MOTOR NEURONE DISEASE

\begin{tabular}{|c|c|c|c|c|c|c|c|}
\hline Patient & Sex & $\begin{array}{l}\text { Age } \\
(y r)\end{array}$ & Side & $\begin{array}{l}\text { Clinician's } \\
\text { opinion }\end{array}$ & $\begin{array}{l}E M G \\
(\text { reflex })\end{array}$ & $\begin{array}{l}\text { Final clinical } \\
\text { diagnosis }\end{array}$ & Comments \\
\hline 1 & $\mathbf{F}$ & 71 & $\mathbf{R}$ & Absent? & $\begin{array}{l}\text { 1. FHB } \\
\text { 2. FHB }\end{array}$ & $\begin{array}{l}\text { None (complaint: } \\
\text { 'heavy legs') }\end{array}$ & $\begin{array}{l}\text { Voluntary contraction of TA; weak } \\
\text { flexion reflex bilat. }\end{array}$ \\
\hline 2 & $\mathbf{M}$ & 51 & $\mathbf{L}$ & Extensor? & $\begin{array}{l}\text { 1. FHB? } \\
\text { 2. FHB? }\end{array}$ & Sciatica $\mathbf{L}$ & $\begin{array}{l}\text { Jerky voluntary toe movements; weak } \\
\text { flexion reflex bilat. }\end{array}$ \\
\hline 3 & $\mathbf{M}$ & 22 & $\mathbf{R}$ & Extensor? & $\begin{array}{l}\text { 1. FHB } \\
\text { 2. FHB? }\end{array}$ & Brachial neuritis $\mathbf{R}$ & $\begin{array}{l}\text { Flexion reflex }+++ \text { bilat., and } \\
\text { brisk flexor response of toes; once } \\
\text { all movements have ceased, hallux } \\
\text { goes 'up' again }\end{array}$ \\
\hline 4 & $\mathbf{F}$ & 21 & $\mathbf{L}$ & Extensor? & $\begin{array}{l}\text { 1. None } \\
\text { 2. None }\end{array}$ & Lumbago & Hallux immobile, little toes down \\
\hline 5 & $\mathbf{F}$ & 43 & $\mathbf{R}$ & Absent? & $\begin{array}{l}\text { 1. FHB? } \\
\text { 2. FHB? }\end{array}$ & Hysteria & $\begin{array}{l}\text { Presented with weakness of } L \text { hand } \\
\text { and both legs and urinary } \\
\text { incontinence }\end{array}$ \\
\hline 6 & $\mathbf{M}$ & 46 & $\mathbf{L}$ & Extensor? & $\begin{array}{l}\text { 1. None } \\
\text { 2. None }\end{array}$ & $\begin{array}{l}\text { Polyneuropathy of } \\
\text { unknown cause }\end{array}$ & Toe movements just possible \\
\hline 7 & $\mathbf{M}$ & 28 & $\mathbf{L}$ & Extensor? & $\begin{array}{l}\text { 1. None } \\
\text { 2. None }\end{array}$ & $\begin{array}{l}\text { Polyneuropathy } \\
\text { (post-infectious) }\end{array}$ & $\begin{array}{l}\text { Flexion reflex }++ \text { bilat.; abundant } \\
\text { voluntary activity }\end{array}$ \\
\hline 8 & $\mathbf{F}$ & 55 & $\mathbf{R}$ & Extensor? & $\begin{array}{l}\text { 1. FHB } \\
\text { 2. FHB }\end{array}$ & $\begin{array}{l}\text { Non-specific oro- } \\
\text { facial pain } \mathbf{R}\end{array}$ & Second toes amputated \\
\hline
\end{tabular}

TABLE 2

PATIENTS WITH SOME EVIDENCE OF CENTRAL NERVOUS SYSTEM DISEASE, IN WHOM EQUIVOCAL PLANTAR REFLEX MIGHT SUGGEST UNEXPECTED LESION

\begin{tabular}{|c|c|c|c|c|c|c|c|}
\hline Patient & $\operatorname{Sex}$ & $\begin{array}{l}\text { Age } \\
(y r)\end{array}$ & Side & $\begin{array}{l}\text { Clinician's } \\
\text { opinion }\end{array}$ & $\begin{array}{c}E M G \\
(\text { reflex })\end{array}$ & $\begin{array}{l}\text { Final clinical } \\
\text { diagnosis }\end{array}$ & Comments \\
\hline 9 & $\mathbf{M}$ & 18 & $\mathbf{R}$ & Extensor? & $\begin{array}{l}\text { 1. None } \\
\text { 2. EHL }\end{array}$ & $\begin{array}{l}\text { Epileptic seizure } \\
\text { two yr ago }\end{array}$ & $\begin{array}{l}\text { Flexion reflex }+++ \text { bilat.; great toe } \\
\text { hyperextends when knee and hip are } \\
\text { flexed against resistance }\end{array}$ \\
\hline 10 & $\mathbf{F}$ & 29 & $\mathbf{R}$ & Extensor? & $\begin{array}{l}\text { 1. EHL? } \\
\text { 2. None }\end{array}$ & $\begin{array}{l}\text { Vertigo and para- } \\
\text { esthesiae of } L \\
\text { arm (cause un- } \\
\text { known); CSF } \\
\text { protein raised }\end{array}$ & $\begin{array}{l}\text { Flexion reflex }++ \text { bilat.; great toe } \\
\text { hyperextends when knee and hip are } \\
\text { flexed against resistance }\end{array}$ \\
\hline 11 & $\mathbf{F}$ & 58 & $\mathbf{R}$ & Extensor? & $\begin{array}{l}\text { 1. EHL? } \\
\text { 2. EHL }\end{array}$ & $\begin{array}{l}\text { Parkinsonism, } \\
\text { dementia, depres- } \\
\text { sion }\end{array}$ & Flexion reflex ++ bilat. \\
\hline 12 & $\mathbf{F}$ & 60 & $\mathbf{R}$ & Absent? & $\begin{array}{l}\text { 1. EHL? } \\
\text { 2. EHL }\end{array}$ & $\begin{array}{l}\text { Chronic vertigo } \\
\text { (brain-stem?); } \\
\text { generalized arterial } \\
\text { disease }\end{array}$ & Flexion reflex ++ bilat. \\
\hline 13 & $\mathbf{M}$ & 62 & $\mathbf{R}$ & Absent? & $\begin{array}{l}\text { 1. EHL? } \\
\text { 2. FHB? }\end{array}$ & $\begin{array}{l}\text { Upper motor } \\
\text { neurone paresis } \\
\text { L leg (unknown } \\
\text { cause) }\end{array}$ & $\begin{array}{l}\text { Flexion reflex }++ \text { bilat., especially } \\
\text { TA }\end{array}$ \\
\hline 14 & $\mathbf{M}$ & 40 & $\mathbf{R}$ & Extensor? & $\begin{array}{l}\text { 1. FHB } \\
\text { 2. FHB? }\end{array}$ & $\begin{array}{l}\text { Hemi-Parkinsonism } \\
\quad \mathbf{R}\end{array}$ & $\begin{array}{l}\text { Hallux immobile, also on electrical } \\
\text { stimulation of FHB; voluntary } \\
\text { flexion possible (long flexor?); } \\
\text { initially suspected of R hemi- } \\
\text { paresis }\end{array}$ \\
\hline 15 & $\mathbf{M}$ & 56 & $\mathbf{L}$ & Extensor? & $\begin{array}{l}\text { 1. FHB? } \\
\text { 2. FHB? }\end{array}$ & Cerebral concussion & Isolated fanning of toes \\
\hline 16 & $\mathbf{M}$ & 57 & $\mathbf{L}$ & Extensor? & $\begin{array}{l}\text { 1. FHB } \\
\text { 2. FHB }\end{array}$ & Presenile dementia & $\begin{array}{l}\text { Jerky toe movements, out of phase } \\
\text { with (weak) flexion reflex; origin- } \\
\text { ally suspected of cerebral tumour }\end{array}$ \\
\hline 17 & $\mathbf{M}$ & 53 & $\mathbf{R}$ & Extensor? & $\begin{array}{l}\text { 1. None } \\
\text { 2. None }\end{array}$ & $\begin{array}{l}\text { Pinealoma and } \\
\text { hydrocephalus }\end{array}$ & $\begin{array}{l}\text { Flexion reflex }++ \text { bilat., especially } \\
\text { TA }\end{array}$ \\
\hline 18 & $\mathbf{F}$ & 39 & $\mathbf{R}$ & Flexor? & $\begin{array}{l}\text { 1. None } \\
\text { 2. None }\end{array}$ & $\begin{array}{l}\text { Transient paresis } \\
\text { 6th and 7th nerve } \\
\mathbf{R}-\text { multiple } \\
\text { sclerosis? }\end{array}$ & Wriggles toes sometimes \\
\hline
\end{tabular}


upper motor neurone disease and, conversely, a negative clinical diagnosis may later appear to be wrong. Especially in that group of patients, however, where the neurologist found unexpectedly equivocal plantar reflexes, but where the EMG showed no EHL reflex and the final diagnosis was also incompatible with Babinski signs, it was possible to explain in many instances why the plantar reflex had aroused false suspicion (see Tables and Discussion). This category of patients is most interesting, as in them the doubtful plantar reflexes are the only reason to suspect organic disease of the central nervous system, and the problem arises how far one should go with ancillary investigations. In other patients, with established supranuclear motor lesions the matter is rather academic. Thus, the 30 patients were subdivided according to the problem arising as a result of the uncertain plantar responses.

1. AN UNEXPECTED EXTENSOR RESPONSE? In eight patients there were possible Babinski signs, which did not fit in with the history and the rest of the neurological examination. The EMG was normal in all of them. In Table 1, the EMG outcome is shown with the neurologist's opinion about the plantar reflex at the time of the study, the final clinical diagnosis, and special features that were noticed during the author's examination of plantar and flexion reflexes. In this and the next group of patients, a dubious extensor response was the clinician's most common choice; those who scored possible flexor or absent plantar responses apparently retained some doubt, since the patient was referred for this study.

2. AN ADDITIONAL EXTENSOR RESPONSE? In 10 patients (Table 2) some clues already implied disease of the central nervous system, but not necessarily involving the upper motor neurones of the side in question, and the neurologist wondered if the equivocal plantar reflex indicated an unexpected localization. The EMG showed EHL reflexes in two, was normal in five, and contradictory in three patients; two of the latter will be discussed below (bilateral Babinski signs without demonstrable cause).

3. THE MISSING FLEXOR RESPONSE Two patients demonstrated unilateral absence of the plantar reflex, perhaps pathological, because for other reasons an intracranial lesion was suspected. EMG recording gave evidence of FHB reflex activity on both occasions in these two patients, and subsequently no cerebral lesion could be substantiated in either of them.

4. AN EXPECTED EXTENSOR RESPONSE IS EQUIVOCAL Ten patients with upper motor neurone lesions showed dubious plantar reflexes on the affected side. In four an EHL reflex was shown by electromyography on both occasions (two probable, two definite), in one only the first time; the clinicians had not rated a possible or definite flexor response in these cases. Of the remaining five patients, an FHB reflex was found in four, no reflex in one. The latter group consisted of two patients with cervical spondylotic myelopathy, two patients with supranuclear paresis of the leg, and one patient who died within a few weeks from a cerebral space-occupying lesion.

\section{DISCUSSION}

VALIDITY OF EMG Of 30 patients with clinically equivocal plantar reflexes, electromyography at one side under controlled ('blind') conditions provided a reproducible outcome in $87 \%$. The final clinical diagnosis may be only a relative criterion for assessing the validity of the EMG result, but in any case the EMG never indicated a pathological reflex when the central nervous system was supposed to be normal. Conversely, a definite or probable EHL reflex could be identified in four out of 10 patients in whom an expected Babinski sign was equivocal. Quite apart from diagnostic considerations, the separate records about the author's previous neurological examination of plantar and flexion reflexes allowed explanation of the difference between the EMG and the clinician's impression of toe movements.

The most frequent fallacies of clinical observation are false-pathological, but in two patients there were bilateral extensor responses which the neurologists tended to disqualify.

FALSE SUSPICIONS The patients shown in Table 1 are the most interesting group. They are usually seen as outpatients. History and neurological 
examination would indicate functional or lower motor neurone disease, but the plantar reflexes create uneasy feelings, which cannot be dissolved by consultation or repeated examination. Should the patient be admitted? If so, a number of ancillary investigations can hardly be avoided, once the suspicion is roused.

In none of the eight patients in this group did the EMG disclose a pathological reflex, and this fitted the subsequent diagnosis. The factors that tended to deceive the clinician could be identified (some of these were also operative in patients from the second group who proved to have normal reflexes):

1. Contraction of TA, voluntary (patient 1) or as part of the flexion reflex (patient 17): the toes go upward passively, without contraction of EHL. This is a classical trap (Oppenheim, 1899).

2. A very active flexion reflex, combined with brisk plantar flexion of the toes: once these bewildering movements have ceased, the big toe goes 'up' (back) to the original position (patient 3).

3 . Voluntary toe wriggling (patients $2,16,18$ ). The jerky extensor movements are inconstant and out of phase with the flexion reflex. Involuntary movements caused by disease of the basal ganglia may also confuse the examiner.

4. The big toe is immobile, while the little toes go gently down; in patient 4 , this probably created an optical illusion.

5. Isolated fanning of toes (patient 15). This 'signe de l'éventail' also occurs in normal subjects (Babinski, 1903) and can lead to errors of both observation and interpretation.

6. Anatomical variations which prevent toe flexion, although the FHB is active. In patient 8 , both second (hammer) toes had been amputated long ago, probably with subsequent shift of the first metatarsal bone and its tendons, as in hallux valgus (Iida and Basmajian, 1974). In patient 14, there seemed to be another abnormality of insertion of the flexor hallucis brevis (FHB), as only isometric contractions could be provoked by stimulating through the recording electrode; voluntary toe flexion was possible, probably mediated by the flexor hallucis longus.

7. Peripheral nerve lesions. The old notion (Babinski, 1898) that a false extensor response can occur as a result of a tibial nerve lesion is less logical than it seems to be: first of all, a pathological recruitment of EHL motoneurones is needed to produce a Babinski sign. However, it is conceivable that a few discharging EHL motor units (rather common in normal subjects, but sparse and asynchronous with TA) can then cause upward quivering of the big toe. This could have happened in patients 6 and 7 , who suffered from polyneuropathy. The FHB, being more distal, is likely to be most involved, and in fact both patients showed scattered EHL activity versus even less and later potentials of FHB in one patient and none at all in the other.

BILATERAL BABINSKI SIGNS WITHOUT DEMONSTRABLE CAUSE Patients 9 and 10 showed rapidly upgoing toes on both sides, embarrassing the neurologist because no specific disease could be found. Patient 9 , an 18 year old waiter, was admitted in 1973 after what was probably an epileptic fit; it has not recurred since then. Patient 10, a 29 year old female attendant for elderly people, complained for two years of almost continuous vertigo and paraesthesiae in her left (dominant) arm; neurological investigation and many ancillary studies did not provide a cause for these sensations, but the CSF protein was raised $(0.93 \mathrm{~g} / \mathrm{l})$ and there was bilateral pes s. $^{\circ} \omega$ cavus. Because the extensor plantar responses i these two patients did not fit easily into the्ष clinical picture and were also unusually fast, if was thought that these might not be 'real Babinski signs.

Electromyography demonstrated a patho logical reflex on only one occasion in bot patients (they account for half of the four EMG inconsistencies), because again the high speed of movement hardly corresponded with the usual criteria.

Clinical examination of the flexion reflex revealed a very low threshold in these two patients, and the upgoing toes were perfectly in phase with contraction of other flexor muscles, although the actual leg movements were less than those of the hallux (both subjects were obese). Tendon reflexes were brisk. In addition, the patients showed hyperextension of the big toe when trying to flex the knee and hip against resistance. This is a 'pyramidal' sign of old $\delta$ vintage (Strümpell, 1887), although rarely present in normal subjects (Brain and Wilkinson, 을 1959), which apparently results from abnormal irradiation to EHL motoneurones of descending impulses originally directed to more proximal ơ flexors. The disinhibited flexion reflex with recruitment of EHL implies a similar pathological spreading of impulses, here of afferent origin. 
The combination, bilaterally, of these two signs (which may be present separately in others) indicates a severe hyperexcitability of spinal cord motoneurones from various sources. This is a typical feature of the isolated spinal cord (Dimitrijević and Nathan, 1967). The two patients in question, however, showed no evidence of a focal lesion, and their motor power was unimpaired. It has to be assumed that in them a diffuse (cerebral?) abnormality is responsible for the lack of inhibition.

MISSING BABINSKI RESPONSE This will generally not present problems of management. When a flexor response is seen where a Babinski sign is expected, EMG will not show a pathological reflex either (unless one is confused by initial plantar flexion of the toes preceding an EHL reflex). A peroneal nerve palsy precludes an extensor response. This may be caused by pressure against the head of the fibula in upper motor neurone paralysis, which also conceals the peripheral lesion (Landau and Clare, 1959); EMG will then often show denervation in EHL (if located) and TA.

USE OF EMG FOR PLANTAR REFLEXES Recording from FHB, EHL, and TA during mechanical plantar stimulation generally provides reproducible results. These make it possible to study patterns of action potentials from separate muscles rather than fleeting, superimposed movements, and to discuss from photographs whether a pathological recruitment of EHL into the flexion reflex (with TA) was present or not. For reliable interpretation some experience with reference groups should be gained. Initially, it appears difficult to ignore the activity of only a few EHL motor units. An important reason for this may be the unusual time base of $500 \mathrm{~ms} / \mathrm{cm}$, 10 times slower than is customary in routine EMG practice, where a similar pattern represents a definite amount of contraction.

In this study, the EMG gave normal results in a great number of patients where equivocal plantar responses, found by the clinician, had created a diagnostic dilemma. So the impression that 'where clinical doubt exists, the plantar reflex is apt to be equivocal' (Matthews, 1970) proved to be true, but in the reverse sense.

This paper by no means advocates the routine use of EMG to classify plantar reflexes; that would be absurd. Differences between EMG outcome and clinical judgements of plantar responses can often be traced back to fallacies of observation and interpretation or to peripheral anatomical factors. This feedback to the clinical neurologist seems to be the most important use of the technique.

CLINICAL CRITERIA Apart from specific errors enumerated above, the following general rules for interpreting equivocal plantar responses emerged from the comparison of clinical data with EMG results.

1. Upward movement of the big toe can be pathological only when it is the result of EHL contraction. This can be reliably checked by inspection of the EHL tendon, which clearly protrudes through the skin when the muscle is active.

2. EHL contraction is pathological only if it occurs synchronously with activity in other flexor muscles. In some subjects the flexion reflex is weak, but usually the tensor fasciae latae or hamstring muscles can be seen to tighten as a reference (it should be kept in mind that the hallux is lighter than foot, leg, or thigh). Walshe (1956) asserted that he had never seen a truly isolated Babinski response.

3. A Babinski sign does not necessarily imply that the concurrent activity of other flexor muscles should be very brisk, and vice versa. A unilateral Babinski response, however, is usually associated with a more active flexion reflex on the same side.

4. Voluntary withdrawal can be confusing. Generally this holds on for some seconds after stimulation, whereas a flexion reflex does not (except flexor spasms, which only occur in severe and chronic lesions). Furthermore, repeated quick stroking of only a few centimetres of skin will, in the case of a flexion reflex, produce each time an approximately similar fraction of the toe and leg movements (some summation may appear), but voluntary retraction will then be abolished or inconstant.

The method of mechanical stimulation scarcely affects the criteria for interpretation of reflex effects. There are local traditions, and sometimes a flexion reflex can be evoked from other parts of the leg than the sole, eponymous or not. However, most techniques employ stroking - that is, temporal and spatial summation of afferent impulses. That slow stroking of the lateral plantar border and plantar arch seems to be most effective (Dohrman and Nowack, 1973) is 
in keeping with this. Sometimes the summating impulses reach EHL threshold only in the last part of the trajectory. Conversely, initial rising of the great toe is followed in some patients by plantar flexion when the stimulus reaches the plantar arch; apparently Hagbarth's principle (1952) that physiological extensor muscles (here: FHB) can be activated from the overlying skin (here: medial plantar border) allows some small variation. Stimulation should not be more distal than the ball of the foot, as it is well known that in some healthy subjects an upgoing toe can be evoked from the base and the balls of the toes (Dosužkov, 1932).

In some cases, interpretation of reflex effects remains difficult, or an anomalous insertion is suspected. Electromyography may then settle the argument, especially when the equivocal plantar response is an unexpected finding.

I am indebted to Dr H. van Crevel for support and many suggestions, to my colleagues for referring their patients, to nurse Tineke Schipper for assistance with experiments and interpretation, and to Miss J. M. Magito for coordinating the study.

\section{REFERENCES}

Babinski, J. (1898). Du phénomène des orteils et de sa valeur sémiologique. Semaine Médicale, 18, 321-322.

Babinski, J. (1903). De l'abduction des orteils. Revue Neurologique, 11, 728-729.

Brain, W. R., and Wilkinson, M. (1959). Observations on the extensor plantar reflex and its relationship to the functions of the pyramidal tract. Brain, 82, 297-320.

Dimitrijević, M. R., and Nathan, P. W. (1967). Studies of spasticity in man. 1. Some features of spasticity. Brain, 90, 1-30.

Dohrmann, G. J., and Nowack, W. J. (1973). The upgoing great toe-optimal method of elicitation. Lancet, 1, 339341.

Dosužkov, T. (1932). The plantar reflex, its signification, the methods of its examination and the causes of some diagnostic errors. Journal of Nervous and Mental Disease, 75, 374-383.

Gijn, J. van (1975). Babinski response: stimulus and effector. Journal of Neurology, Neurosurgery, and Psychiatry, 38, 180-186.

Hagbarth, K. E. (1952). Excitatory and inhibitory skin areas for flexor and extensor motoneurones. Acta Physiologica Scandinavica, 26, suppl. 94, 1-58.

Henneman, E., Clamann, H. P., Gillies, J. D., and Skinner, R. D. (1974). Rank order of motoneurones within a pool: law of combination. Journal of Neurophysiology, 37, 13381349.

Iida, M., and Basmajian, J. V. (1974). Electromyography of hallux valgus. Clinical Orthopaedics and Related Research, 101, 220-224.

Landau, W. M., and Clare, M. H. (1959). The plantar reflex in man, with special reference to some conditions where the extensor response is unexpectedly absent. Brain, 82 , 321-355.

Matthews, W. B. (1970). Practical Neurology, 2nd edn, p. 209. Blackwell: Oxford.

Nakanishi, T., Shimada, Y., and Toyokura, Y. (1974). An electromyographic study of the pathological plantar response. Journal of the Neurological Sciences, 23, 71-79.

Oppenheim, H. (1899). Discussion following W. Koenig $\overrightarrow{\mathbb{D}}$ (1899). Ueber die bei Reizung der Fussohle zu beobachtenden Reflexerscheinungen mit besonderer Berücksichti gung der Zehenreflexe bei den verschiedenen Formen der cerebralen Kinderlähmung. Berliner klinische Wochen schrift, 36, 822-823.

Strümpell, A. von (1887). Ueber einige bei Nervenkrankenō $\vec{\theta}$ häufig vorkommende abnorme Mitbewegungen im Fusse? und in der Zehen. Neurologisches Zentralblatt, 6, 1-4.

Walshe, F. M. R. (1914). The physiological significance of the reflex phenomena in spastic paralysis of the lower limbs. Brain, 37, 269-336.

Walshe, F. M. R. (1956). The Babinski plantar response, its forms and its physiological and pathological significance. Brain, 79, 529-556. 